\title{
Deconstructing the Seven Cs of Social Media: A Summative Perspective
}

\author{
https://doi.org/10.3991/ijim.v14i03.10490 \\ Sonica Rautela ${ }^{(凶)}$, Dr. Tarun Kumar Singhal \\ Symbiosis International (Deemed University) Pune, India \\ sonica.rautela@scmspune.ac.in
}

\begin{abstract}
One of the defining technological forces which are reshaping the world today is the easy accessibility to the Internet. The Internet has changed the way people communicate with each other. Social media whose development was first marshaled by Web 2.0, has revolutionized the entire world of communica-tion. The most intriguing fact is that the world of social media is constantly changing. The platforms which are topping the charts today may not be tomor-row. Also, it can be observed that the power has shifted from the hands of mar-keters to the hands of users which in turn have empowered users. The objective of the present study is to explore the different facets of social media in detail. These facets form the base for the world of social media and can be referred to as the $7 \mathrm{Cs}$ of social media. These seven Cs are - content, community, conversation, capital (social), culture, collaboration, and conversion respectively. With an en-hanced understanding of all these Cs of social media, the study proposes a con-ceptual model depicting the relationship between these seven Cs and social me-dia. Companies should analyze each of these Cs in detail and design their social media strategies accordingly. This will not only assure the efficient and effective use of social media but also will help managers to decide where and how to allot firm resources in a better fashion.
\end{abstract}

Keywords - Social Media, Conceptual Model, Content, Community, Conversation, Social Capital, Culture, Collaboration, Conversion

\section{$1 \quad$ Introduction}

The captivating and mesmerizing platform of social media has changed the entire world of communication. It has altered the way the firm communicates and interacts with its customers and also how customers communicate within themselves. It has great popularity among its users [1]. The Internet has revolutionized the entire planet in many ways. It is becoming a natural, background part of everyday life at a very rapid pace [2]. Marketers have long understood the power of interaction with the customer but with the new customer empowered environment, they are still struggling to steer their boat.

The world is moving from the era of Web 3.0 which is characterized by factors like Artificial Intelligence (AI), semantic web, enhanced web, 3D web towards the era of 
Web 4.0 which have been defined by words like big data and augmented reality [3]. In today's era, the power has completely shifted online. Information and communication are no longer the territories of the marketers who use to bombard customer with 'static corporate content' [4] to the zestful and spirited interaction completely driven by the users and customers.

Web 2.0 is the procreator of social media and can be explained as platforms that allows the creation and exchange of contents generated by the users ignoring geographical boundaries. It includes arrays of a platform like blogs, social networking sites (SNSs), virtual game worlds, collaborative projects, chatting apps, content communities, photo-sharing networks, lifestyle networks, business networks and so on. Social media is an interactive platform that allows and facilitates users to exchange ideas of common interest. Users can upload information, like (or unlike) it and can share using this Web 2.0 based platform that promises better collaboration and communication within and outside an organization [5]. Among all the categories of social media, social networking sites (SNSs) have become more popular and favored one in present times.

The first recognizable Social Networking Site (SNS) was SixDegree.com and was launched in the year 2007 [6]. Since their introduction, social media was successful in attracting a gargantuan number of followers and users. The numbers are still towering at a rapid pace. As per the online statistical portal - Statista (2018), one of the most popular Social networking Site (SNS) worldwide is Facebook and has 2.23 billion monthly active users as of October 2018 while in 2010 the number was 608 million [7]. Keeping into account the growing number of users more and more companies are including social media into their communication program so that they can drive digital engagement with customers [8].

\section{Seven Cs of Social Media}

The world of social media is much larger than it seems to many of us. The most intriguing fact is that this world is constantly changing. The platforms which are charttopping today may not be tomorrow. Thus, the Facebook of today can be Friendsters and MySpaces of tomorrow [9]. Among these platforms, few are very popular worldwide (example- Facebook), while some are popular within a specific geographical region or among certain age groups or interest groups. For example- WhatsApp a mobile messaging app founded in 2009, is very popular in countries like India, Brazil, Mexico $\&$ Spain [10] while in the USA it has a very small number of users [7]. Also, few platforms are not so popular or have become obsolete with the launch of some more innovative and contemporary platforms. For example- Orkut became history as soon as Facebook started residing in the hearts and minds of the users.

The detailed study and in-depth analysis of factors which fabricate social media and govern the success and failure of this platform reveal that any social media platform rests on the shoulders of seven Cs. These seven Cs include- content, community, conversation, capital (social), culture, collaboration, and conversion respectively. The de- 
tailed explanation and their relevance in social media platforms are discussed as follows. Also, the study proposes a conceptual model depicting the relationship among these seven Cs which are of interest for the present study.

\subsection{Content}

The first ' $\mathrm{C}$ ' of social media is 'content' which can also be referred to as foundation or linchpin of the social media. The massive amount of content is created and uploaded every day in diverse platforms. The content is either created by the users or by the firms. The content which is created by users is termed as User Generated Content (UGC) and the content generated by firms are referred to as Firm Generated Content (FGC) (Figure 1).

User Generated Content (UGC): The phenomenon of User Generated Content (UGC), received much of the attention in the year 2005 with the arrival of Web 2.0 technology. As a matter of fact, the ability of the users to generate content is what differentiates social media from traditional media [1]. Every day millions of users generate content in a different format such as photos, videos, articles, personal or professional information, messages, short text messages (called tweets), voice messages etc. They upload and share this content using different platforms such as Facebook, YouTube, Twitter, WhatsApp, LinkedIn, Myspace and many more. The motivating factors for users behind creating, sharing or uploading the content on social media can be varied. UGC can play a vital role in various aspects of marketing. For example- it can enhance customer engagement with the brand, can reinforce the customer-brand relationship, can build trust, increase the number of brand followers on various social media platforms and so on.

Firm Generated Content (FGC): The extraordinary reach of social media has compelled the marketers to include social media as a part of their marketing communication mix. Therefore, the firm also generates messages and content on their official social media pages which are termed as Firm Generated Content (FGC) [11] or Marketer Generated Content (MGC) [12]. Vividness, interactivity \& entertainment of the content posted by the firms play a vital role in enhancing the word of mouth reach and popularity of any social media platform [13]. FGC can help the firm maintain one to one relationships with the customer because of the interactive nature of social media and is proved to effects the behavior of consumers in a positive manner. The effect is greater for customers who are tech-savvy; more experienced and uses social media in their day to day life [11].

Both the above-mentioned categories are depicted in figure 1. Also, as apparent from figure 1 , there are different forms of incentives associated with the creation of UGC and are broadly categorized into two types- implicit incentives and explicit incentives. Implicit incentives are intangible in nature and provide users with intangible benefits for example- feeling good, social capital and so on. Explicit benefits are tangible rewards like - coupons, voucher, lotteries etc. which can be financial or prize draws in nature [14]. Figure 1 also reveals that the firm generated content or marketer generated content can be informative, persuasive or promotional in nature. The content generated by the marketer is proved to have a significant and positive effect on product sales. 


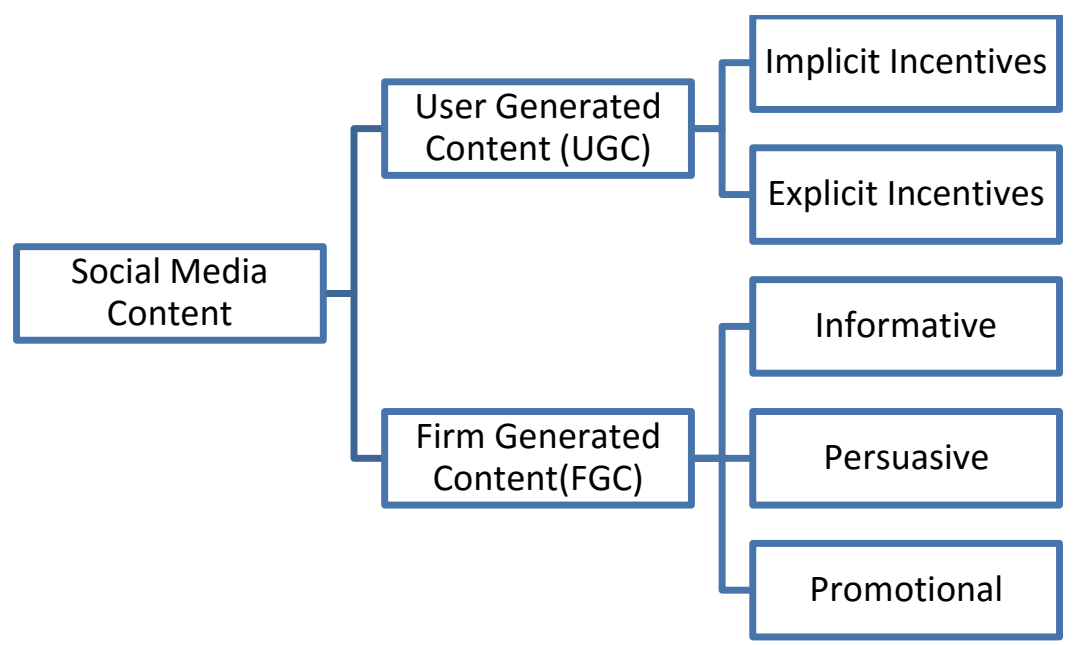

Fig. 1. Content types (Authors own)

For a product that requires low involvement from the part of the customer, persuasive and promotional content serves a better purpose while in case of high involvement products informative MGC was proved to be more effective. However, in order to make a decision, the consumers seek both user-generated contents as well as firm generated content [12].

A platform or any marketing strategy cannot be successful without great content [1]. Thus, content is imperative for the success story of any social media platform. (Voorveld et al)[8] While examining how consumer engagement with social media platforms drives engagement with the advertisement present in this platform was of the view that "on social media, the context (i.e., the platform), not the content, of advertising is a key determinant of its effectiveness." This means that in social media advertising the platform becomes more important than the content of advertising. Thus, the advertisers should understand the pros and cons of different media platform and choose the platform which matches the goal and message of the advertisement [8]. Also, as explained by Zhu and Chen (2015) [16], one of the reasons for the ineffectiveness of social media marketing can be the incompatibility between the nature of social media and marketing motives. In most of the cases, users go to social media to connect with people while marketers go to sell things. These two motives do not go along with each other [16]. Therefore, while designing the content marketers should understand and try to align the marketing motives with the need of customers and nature of social media. Also, they must create content that attracts attention, develop users" interest, create users desire to engage and stimulate their action of engagement with the firm. 


\subsection{Community}

Humans are a social being and by default have been programmed to be active in their present social settings. However, the extent of individual involvement in the social activity is a function of many factors like personality, age, culture, belief systems and values and so on. People have always been striving to connect and create networks with other people. In this era of digitalization users who share a certain common interest (Myspace, Flixster, Care2) or sometimes not having same interest areas (Facebook, WhatsApp, WeChat) come together to form online communities. Communities in terms of social media can be defined as the digital destination that allows the people to engage and share their experiences with each other aloof of which part of the world they belong [17]. In the present world of internet their 'exist a rich and diverse ecology of social media sites' which varies on a different basis such as scope and functionality [18]. For example, content communities like YouTube (for videos), Flickr (for photos) and SlideShare (for sharing powerpoint presentations) main objective is to share content between various users [19]. These content communities exist in different media types and generally do not follow any geographical boundaries.

Kietzmann et al. (2011) [18] proposed that in the case of social media two different types of the group can be identified. In the first category of groups' individuals have the authority to sort their contacts and place their friends or followers into different selfcreated groups. The second type of groups can be open to everyone or may require invitation or permission of the administrator to join.

Brands have also realized the importance of brand communities and therefore more and more brands are using social media as a platform to engage in dialogues with their customers and build brand communities. Brand communities have been proved to have positive effects on communities' makers as well as it enhances the brand loyalty of consumers towards the brand [20]. Organizations should always try to foster a sense of community among users as this helps people to build a sense of belongingness towards the organization.

\subsection{Conversation}

Conversation is the pillar that drives everything in a social media platform. It is how users of a particular social media platform participate in the communication process with each other in a social media setting [4]. Social media has become an important platform to cultivate the meaningful relationship between firms and their customers [21], [22]. Understanding social media from the perspective of public communication is not only cardinal but it is pertinent to political communication also [23]. The conversation should be built upon the pillars of engagement and interaction and should have truth and transparency as its core guiding philosophy. Engagement in social media is the sum total of social media experiences. The experiences which form social media engagement are defined as the 'emotional, intuitive experiences or perceptions that people undergo when using a particular medium at a particular moment.' These experienced set can be multifaceted, such as satisfying the informational need, sharing something (photos, views, comments etc.) to others or fritter away time [8]. 
Gallaugher \& Ransbotham (2010) [21], have explained this conversation as a customer dialogue. In order to analyze this social media customer dialogue, they developed a 3- $\mathrm{M}$ framework. According to these researchers, there are three important flows of customer communication which includes:

- Firm to customer communication (Functioning as a Megaphone): In this case, the firm act as the genesis of communication and share the messages with the world using social media, thus playing the role of a megaphone.

- Customer to firm communication (Functioning as a Magnet): Social media not only aid in the dissemination of information by the firm but also evoke customer reaction and communication. The customer reaction can take many forms such as feedback, comment (positive as well as negative), likes or dislikes, new product features and so on. In this case, the firm uses social media for inbound communication, thus acting as a magnet to customer communication.

- Customer to customer communication (Functioning as a Monitor): Social media also allows the firm to have an insight into the customer-to-customer conversation. This aids the firms to get an insight into the marketing environment and peep into the black box of the consumer.

All these above-mentioned customer communication flow works in synergy and creates ample opportunities at various levels and ways. Thus, social media is an excellent medium for conversation and exchange of dialogues.

\section{$2.4 \quad$ Capital (Social)}

Social capital is a multifaceted approach and is a concept that cannot be easily defined [24]. Durlauf (2002) [25] was of the notion that social capital is an elusive concept as there has not been a consensus regarding its definition. The termed 'social capital' was first defined by late James Coleman, one of the first social scientists in the 1970s. According to him "social capital initially derives from social theory and from the broad idea that social relationships are resources that help people act effectively". Social capital can be considered as a by-product of social relationships that exist among members of society and aids the members in achieving mutual goals through cooperation and support to each other. In other words, it is the outcome of social relations and a mandatory precursor of social capital [26].

Durlauf (2002) [25] came up with three main points regarding social capital. These are:

- Positive facets are generated by social capital for the members of a society or community.

- The positive facets are developed due to the norms, trust, and values shared by the members and their effect on expectation and behavior of people and

- Shared trust, norms and values arise from informal forms of organizations based on social network and associations [27]. 
It was also found in one of the studies that social capital is very closely knitted to the concept of civic engagement (the extent to which members of society involve themselves in a community) and mutual trust among the members of a community [28].

Figure 2 depicts various dimensions of social capital. These dimensions are the result of the strong personal relationship among the members of a community. Also, this relationship not only provides the members with a valuable resource to conduct their day to day social affairs but also empowered them with the credibility of various forms [29]. The dimension depicted in figure 2 can be broadly divided into two components cognitive component such as - values, norms, attitude and beliefs, sense of belongingness etc. and structural component which includes externally observable aspects such as density and pattern of the social network in a social organization such as diversity and social network configuration. However, Nahapiet and Ghoshal (1998) [29], in order to explore the role of social capital in the creation of intellectual capital has considered three clusters of all these facets i.e. the structural, the relational and the cognitive dimensions of social capital.

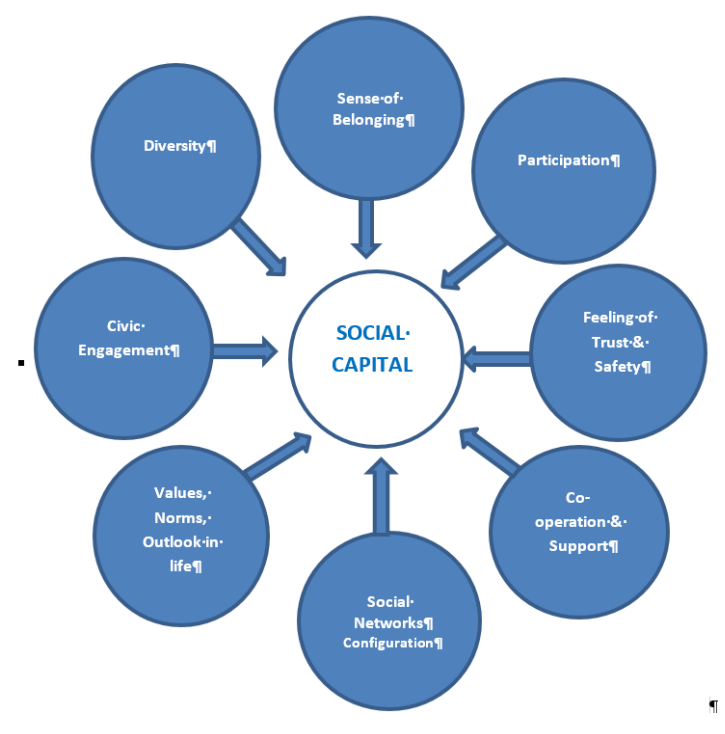

Fig. 2. Dimensions of Social Capital (Authors own)

Islam et al. (2006)[27] advocated that social media has two distinct type (refer figure 3 ) - horizontal, which exist between people sharing the same status or are more or less equal and vertical which prevail as a result of unequal relations and hierarchy (based on income, power, status or any other criteria) in the social system. The horizontal social capital can be further divided into two - "bonding" social capital and "bridging" social capital. Bonding social capital refers to those ties which are shared by near and dear ones for example- family, friends, neighbors' and so on. These ties are strong in nature and are shared by homogenous groups while bridging social capital is shared by a heterogeneous group of people and is weak in nature. These ties link people belonging to a different occupation, ethnic group, social class etc. [27], [30]. Social Media can be 
said as a "catalyst" of bridging social capital as it facilitates the formation of ties which are not hedged by any geographical or distance boundaries.

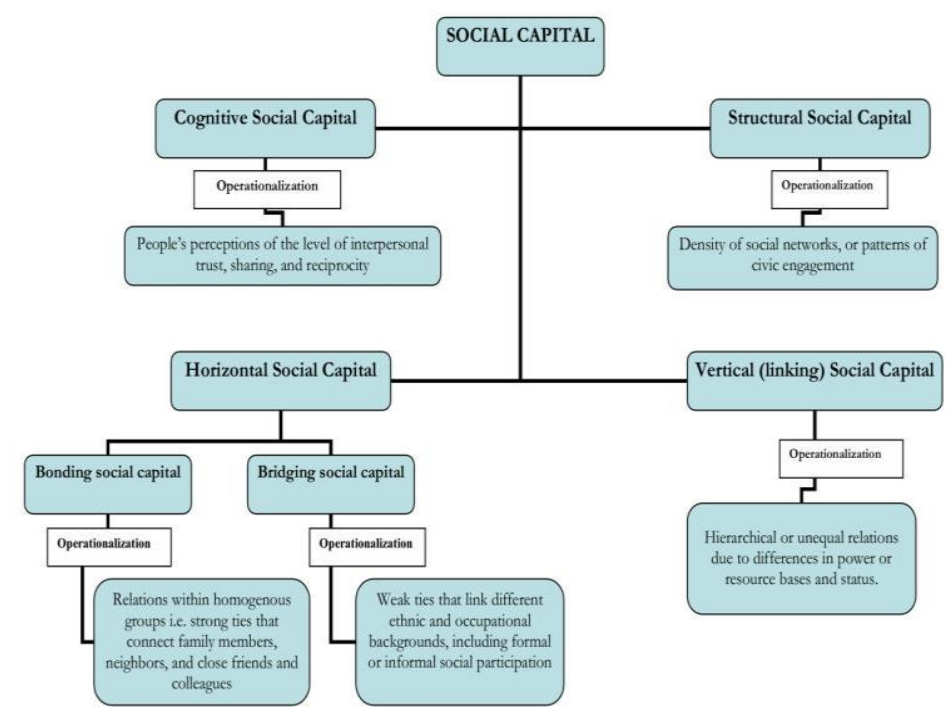

Fig. 3. Different types and dimensions of social capital with the operationalization of the notion in empirical studies [27]

Ellison et al. (2007) [31] were of the view that with the change in the relationship (formed or abandoned) social networks tend to change. Significant changes in social network led to a change in the social capital of the individuals such as movement from one geographic location to another. In such cases, Internet technologies aid individuals in maintaining the social ties with the people belonging to previously inhabited location or community which they called as "maintained social capital".

Social Capital has also been studied with respect to internet usage. The internet and online technologies have been associated with a decrease as well as an increase in social capital [31] [32]. Few studies have concluded that the use of the internet has diminished face to face interaction [2] or have resulted in a reduction in interpersonal interaction and communication [33]. However, many studies have also proved that Internetmediated technologies have resulted in well-being and the creation of social capital. According to Valenzuela et al. (2009) [32], social capital is affected by the specific way the technology is used by the individual and not by the technology per se. While examining the use of SNSs, social capital was found as one of the relevant outcomes. These SNSs aims at the formation and connection of social ties between people [26]. In one of the studies on university students, Facebook users have been proved to be positively 
associated with the creation and maintenance of social capital. Also, Facebook usage was found to be related to psychological well-being, suggesting that it was very beneficial for the students experiencing low-esteem and low levels of life satisfaction [30][31][34]. In another study, the intensity of Facebook usage in students was positively related to life satisfaction, social trust, civic engagement, and political participation. All these factors are related to attitude and behavior that enhance the social capital of an individual [32]. Facebook usage has been proved as having no detrimental or malign effect on student performance within a course and perhaps the students who have more connections in this network have positive links with the success factors such as summative grades, staying with the course and achieving well [35].

A study was done on WhatsApp (a mobile messaging app for smartphones founded in 2009) confirmed that the well-being factor along with WhatsApp attitude and intention to use affects the social capital gain by the students while using this instant online messaging app. Also, the researcher was of the view that users follow the same pattern of behavior in both real as well as virtual worlds [36]. Thus, it can be concluded that social capital is an important outcome for individuals using social media platforms.

\subsection{Culture}

Culture can be simply defined as "the collective values, customs, norms, arts, social institutions and the intellectual achievements of a particular society" [37]. However, the present definition does not satisfy many aspects of culture. Also, the word culture has been derived from anthropology and organizational research, researchers and scholars have offered more than 250 definitions of culture [38].

Communication is an inevitable part of the culture. How individuals communicate, use verbal or non-verbal communication depends a lot on the culture they belong to. The same sign, symbols, gestures, color may have a different meaning in different cultures of the world. Throughout the history of humans, new technologies have had a consequential impact on culture. The same is true in the case of the Internet and social media also. Internet and social media have the power to impact human behavior and impact culture [39]. For example- last few months have witnessed many cases related to misinformation, rumors and fake news circulated on WhatsApp in India. This has led to unrest in society, mob fury and triggering violence in certain parts of the country. This clearly proves that communication in social media platforms impacts human behavior. Social media and information and communication technologies (ICTs) have also been studied as a tool of openness and anti-corruption for societies and thus leading to a culture of transparency [40].

Our everyday life has now been entangled with the Internet and social media. As a result of the exponential growth in social media platforms, small as well as big companies are incorporating social media into their marketing communication strategy so that they can stay connected with their users. Also, the social media platforms are connected in one way or the other, which has resulted in a whole new ecosystem of related media consisting of a large number of small players as well as few big players. This all has led to the formation of culture which was termed as 'culture of connectivity' by Van 
Dijck (2013) [41]. This culture of connectivity has evolved in the last few decades and has become an inherent part of our day to day life.

Social media has empowered users with the power of participation and aids in sharing 'our mental landscape, our memories and identities, our heritage and culture' not only to the people around us but to the people across the world [42]. As a result, there are lots of changes worth noticing in cultures around the world due to social media. The presence and flourishing online dating site are a classic example of 'how the construction of significant relationship can draw on the resource provided by social media' [39] Thus, social media has contributed to the creation of a global and shared culture. In other words, the contemporary culture is a mix of "virtual" with the "real".

\subsection{Collaboration and co-creation}

Today, firms are facing a competitive environment that is intense, global and very dynamic in nature. New products which can fulfill the needs and expectation of the customer with greater efficiency and proactively provide an important competitive edge to the firms and become an important factor in driving the market pull toward themselves [43]. New products are vital for the growth and prosperity of any firm is well recognized by many researchers in their studies [44].

Cooper and Kleinschmidt (1995) [45] proposed that a company's overall new product performance depends on the following elements: the NPD process and the organization of the NPD program; the strategy of the firm related to NPD; the firm internal environment: culture and climate driving innovation and the upper-level management level of commitment to NPD. Inculcating users' voice during NPD stages have been proved to be positively related to NPD performance [46].

The transformations in the world of information and communication technologies (ICT) have led to the drastic conversion in the relationship between customer and producer with important innuendo to the new product development [47]. Traditional marketers used to look at new product development (NPD) as an 'internal firm-based process' in which the role of the customer is relatively passive. However, with this new paradigm of co-creation customer can hold a central position in the NPD process and are capable of creating new products [48].

Social media represent a revolutionary trend [19] which is of great interest to the firms operating in the marketplace (physical) or marketspace (virtual). One of the amazing features which distinguish social media from traditional media is its ability to collaborate with different stakeholders. This collaboration can result in the co-creation of products and offerings by the marketer to the consumers. Also, this collaboration provides more 'meaningful relationships' and 'dynamic connection' between the consumers and the firms [49]. Consumers involved in co-creation feel more empowered and are more willing to participate in future ventures for virtual new product development [50]. 


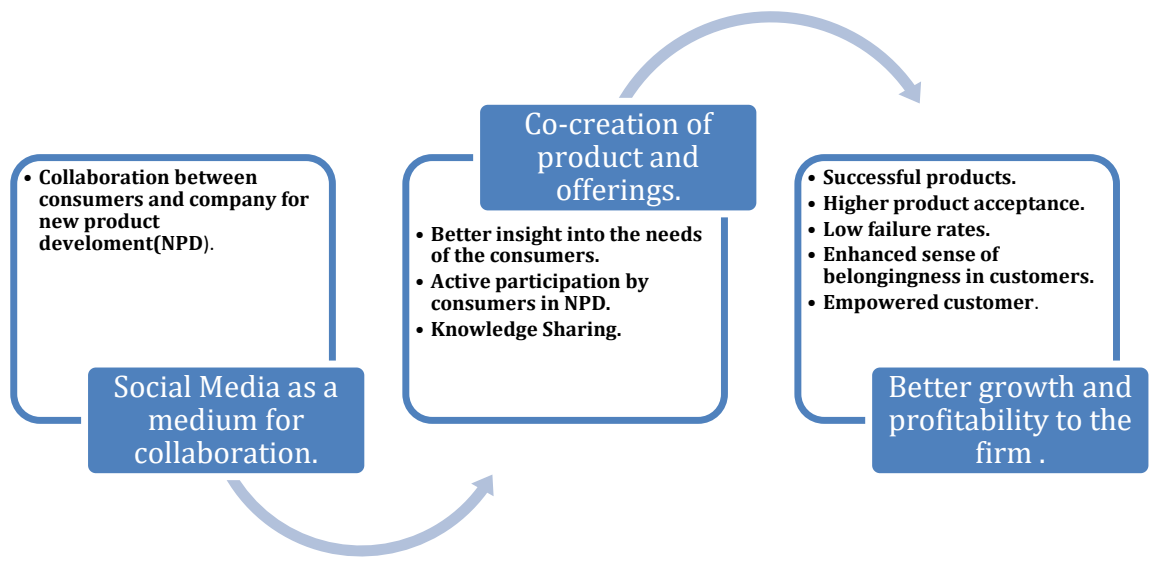

Fig. 4. Collaboration and co-creation via social media leading to growth and profitability of the firm (Authors' own)

Figure 4 illustrates the process of collaboration and co-creation using social media. As depicted by figure 4 social media can be used as a platform to collaborate and cocreate new products and offerings. Co-creation is an active, creative and participative process where both firm and consumer together define, generate and develop value in context to NPD [51]. It provides firms with an opportunity to interact with the stakeholders from the external world and to have a detailed insight into their needs and wants [52]. As a co-creator, consumers are not only the receiver of products designed and created by marketers but also an 'active' participant in designing and developing new products. This entire process of co-creation helps in getting a better insight into the consumer needs and wants, thus humanizing the new product development (NPD) process [53]. This also promotes knowledge sharing between firms and their customers. As a result of active participation by the customers, the new product development process effectiveness and innovativeness [54] is enhanced. Also, this active participation mitigates the risk of product failure and amplifies the chances of new product success [55] [56]. The customer in the entire process feels more empowered [50] [57] and their sense of belongingness with the firm is also enhanced [53].

Kao et al. (2016) [49] proposed a five-stage- model of co-creation leveraging social media. The stages proposed include: Interact, Engage, Propose, Act and Realize. Chan, Yim, and Lam (2010) [58] while examining the customer participation and its relation to performance outcome of employee concluded that promoting customer participation could be a 'double-edged sword'. On one hand, it enhances customers' economic value 
attainment and reinforces the relationship between customer and employees while on the other hand it may lead to job stress and may obstruct job satisfaction of employees.

\subsection{Conversion}

The final ' $\mathrm{C}$ ' of social media is conversion i.e. return of investment (ROI). Companies are spending a huge amount of money on social media and therefore it is obvious that they look for a return on their investment. Fisher (2009) [59] referred return on Investment (ROI) as the "Holy Grail" of social media. Marketers, on one hand, feel the pressure to use social media as a part of their marketing communication mix while on the other are asked to justify the cost using traditional media metric. There are few metrics like page viewed, total likes, total downloads or unique site visitors which give an idea but not a complete picture of return of firm investments in social media related platforms [59]. According to [60] Alston (2009), use of traditional or conventional metrics to measure social media output would be similar to "sticking a square peg in a round hole" [60].

In the case of social media, calculating ROI is not possible without ROC i.e. return on a conversation (ROC) [15]. According to Evans (2011) [9] in the case of social media, the conventional approaches to measure success need to be changed. It is all about ROC or return on conversation rather than ROI or return on investment in case of social media. Hoffman and Fodor (2010) [61], were of the view that companies should forget ROI in case of calculating or judging the impact of social media marketing. Instead they should follow a head down approach where "instead of emphasizing on their own marketing investment and calculating response in terms of customer response, managers should begin by considering consumer motivation to use social media and then measure the social media investments customers make as they engage with the marketers' brand"[61]. Thus, the returns will be in the form of consumer behavior tied towards a particular social media application rather than purely in forms of dollars earned by companies.

The same was also reinforced by Jason Falls in Social media explorer. According to Falls (2008) [62], the ROI in case of social media should not be measured because social media is not about money but about people and this people-centric approach is the reason for the success of social media. All the buzzwords like conversation, community, dialog or sharing are consumer centric and thus social media is not about sales or profit [62].

It was also found that the company ROI can be improved by identifying and recruiting potential brand ambassadors in the online social media platform who are influential and interested in company products and offerings [63]. Thus, social media outcomes are different and cannot be measured by traditional methods. The need of the hour is to see a broader picture and not to focus only on the dollar earned by the firm using a social media platform. 


\section{Conceptual Model - Analysis and Discussion}

Figure 5 shows the conceptual model illustrating the relationship between the above mentioned seven Cs and social media. The analysis and discussion of the model are as follows.

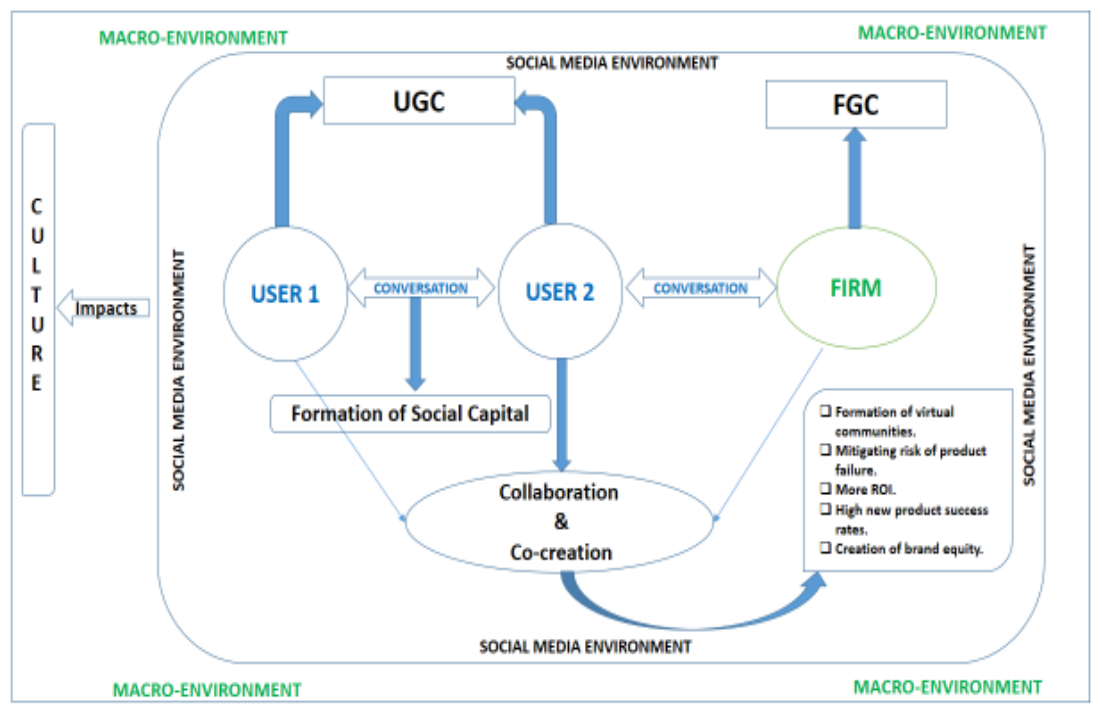

Fig. 5. Conceptual Model depicting Cs of Social media (Authors'own)

Social media differs from traditional media on various fronts. One of the key points which differentiate social media from traditional media is its interactive nature. Social media provides a platform where information in the form of communication flows freely. This flow of information is bidirectional that is from consumers end to firm's end and vice- versa. Also, the information flows between different consumers across different parts of the world. Firms, in order to keep pace with the changing environment are increasingly using social media to foster their external communication with its consumers [64]. However, this interaction happens in an environment which is highly mutable and erratic in nature and can be referred to as social media ecology [4] or social media environment. This social media environment is rich and diverse with different types and categories of social media platforms such as blogs, Social networking sites (SNSs), virtual communities, virtual games, collaborative projects and so on.

Users (User 1 \& User 2 in figure 5) use social media and different types of social media platforms to interact with each other as well as with the firms. Users in this process of interaction create, share and upload content of their and others interest in the social networking platforms they are using. The content generated by the users is termed as 'user-generated content' (UGC). UGC can be of different formats such as pictures, videos, text, audio, graphics etc. Today, in order to engage with its users' firms also 
create content that is either informative, persuasive or promotional in nature. The content generated by the firm is termed as 'firm generated content' (FGC).

The interaction of users in the social media environment facilitates the formulation of social capital which is a natural outcome of social interaction between users. This capital (social) is a treasured resource for conducting social affairs and aids in the survival of individuals. Social capital rests on the pillars of trust, cooperation and collective action of the members of the community [29] which in today's era can be a real or a virtual community. Social media also facilitates two-way communication between the firm and its users. Therefore, users are not only the passive receiver of a message from the firm but also can voice their messages using social media as a platform. Thus, the social media act as an interactive platform which can be used and in near past is increasingly be used by the firms to get an insight about their users and customers. The use of social media as a platform enhances the collaboration and co-creation process between the firm and its users. Also, inculcating the voice of the consumer, on one hand, minimizes the risk of product failure while on the other enhances customer participation in the new product development process.

The enhanced customer participation cultivates a sense of belongingness among the users and they feel more connected with the firm. This helps the firm to create more brand equity and building brand loyalty among its users. The highest level of brand equity is brand resonance [65] i.e. the long-term relationship of the firm with the users. The consumer feels connected and becomes the promoter of the brand in their day to day life. This relationship is also manifested in form of communities which are also referred to as 'brand communities.' Also, users sharing the same types of interest, passion, hobbies etc. form online virtual communities in order to share their views, experiences, concern etc. These online communities are beyond geographical boundaries and act as a platform for free interaction between users of different parts of the world. In other words, social media "is a democratic platform to voice opinions and create communes" [66]. The free flow of information is a vital element for the social media environment. All this free flow of information stirring in the social media environment impacts the culture by and large as communication is an inevitable part of our culture. Any variation in the world of communication apparently impacts culture. Also, social media has created a 'culture of connectivity'. This has also given birth to brands that are not driven by needs or emotions but by purpose. Also, the interaction between various stakeholders on social media platforms influences the equity of the firm in a positive or negative manner thus impacting the firms return on investment. This return on investment is in real sense 'return on a conversation' which is qualitative and cannot be measured in quantity. Also, this return on conversation influences the long-term sustainability and profitability of the firm.

\section{Managerial Implication}

Social media is one of the crucial communications touch-points for firms. In the contemporary highly connected world, presence in social media becomes imperative for any firm. Without social media presence, a firm loses an opportunity to interact with 
its present and potential customers [23]. Therefore, a detailed understanding of the world of social media is mandatory. Also, embedding social media into the organization has the potential to change the relationship of the company with its consumers [67]. The customer engagement is also found to be correlated with the trust that a customer has on company's product/brand/offering [68]. Few studies have also associated the success of the organization with the effective utilization of social media [69]. The current study attempts to present a detailed insight into the seven Cs of social media. The detailed understanding of these Cs will aid managers in devising their social media marketing strategy. The study also proposes a model that consolidates all these seven Cs into a framework. The framework attempts to present an insight into the relationship of all these $\mathrm{Cs}$ with each other. This relationship aids marketers in designing their social media strategy and garnering the benefit of social media.

\section{Conclusion}

It is indisputable that social media has become one of the powerful engines for the success of businesses in today's digitalized and super connected world. It is therefore mandatory for firms to inculcate social media into their marketing communication strategies. But what is important to note is that whether the social media platform is super hit or obsolete, mature or contemporary, general or specific to certain interest groups, the fundamentals of social media sits on the shoulders of seven Cs i.e. Content, community, conversation, capital (social), culture, collaboration, and conversion respectively. Most of these Cs directly or indirectly contribute to the success quotient of the firm. Thus, to use social media platforms effectively and efficiently firm should analyze each of these Cs in detail and design their social media strategies accordingly.

The present paper was an endeavor to present a detailed insight of the seven Cs of social media and propose a conceptual, theoretical based model that relates all these Cs. Also, the paper presents an insight into the managerial implication of this model. However, there are few drawbacks associated with the study. As is evident from the nature of social media, this world of social media is constantly changing and is prodigious. Therefore, a continuous exploration and study of this field are required. This will not only open new avenues of interest every time but will also strengthen our knowledge regarding usage of social media platforms for customer engagement and two-way communication between the firm and its customers. In future, the model can be empirically tested. This will contribute to strengthening the model further. Also, the empirical testing of the relationship between the various Cs and their role or impact on firms' social marketing strategies will be an interesting future research avenue.

\section{References}

[1] M. Drahošová and P. Balco, P, "The analysis of advantages and disadvantages of use of social media in European Union”, Procedia Computer Science, vol. 109, 1005-1009, 2017. https://doi.org/10.1016/j.procs.2017.05.446 
[2] J. Bargh and K. McKenna, "The Internet and Social Life", Annual Review of Psychology, vol. 55, no. 1, pp. 573-590, 2004. Available: 10.1146/annurev.psych.55.090902.141922.

[3] I. Maida, "What is web 4.0?" criticalcase.com, 2018. [Online]. Available on https://www. criticalcase.com/blog/what-is-web-4-0.html.

[4] J. Kietzmann, B. Silvestre, I. McCarthy and L. Pitt, "Unpacking the social media phenomenon: towards a research agenda", Journal of Public Affairs, vol. 12, no. 2, pp. 109-119, 2012. Available: https://doi.org/10.1002/pa.1412

[5] S. Andriole, "Business impact of Web 2.0 technologies", Communications of the ACM, vol. 53, no. 12, pp. 67, 2010. Available: $10.1145 / 1859204.1859225$.

[6] D. M. Boyd and N. Ellison, "Social Network Sites: Definition, History, and Scholarship", Journal of Computer-Mediated Communication, vol. 13, no. 1, pp. 210-230, 2007. Available: https://doi.org/10.1111/j.1083-6101.2007.00393.x

[7] Statista - The Statistics Portal. Statista.com, 2018. [Online], Available on https://www.statista.com[Accessed May 2018]. https://doi.org/10.5260/cca.199318

[8] H. Voorveld, G. van Noort, D. Muntinga and F. Bronner, "Engagement with Social Media and Social Media Advertising: The Differentiating Role of Platform Type", Journal of Advertising, vol. 47, no. 1, pp. 38-54, 2018. Available: https://doi.org/10.1080/00913367. 2017.1405754

[9] L. L. Evans, Social Media Marketing: Strategies for Engaging in Facebook, Twitter \& other Social Media. Pearson Education India, 2011.

[10] N. Aharony, "Why do students use What's App? - an exploratory study", Aslib Journal of Information Management, vol. 67, no. 2, pp. 136-158, 2015. Available: https://doi.org/ 10.1108/ajim-11-2014-0148

[11] A. Kumar, R. Bezawada, R. Rishika, R. Janakiraman and P. Kannan, "From Social to Sale: The Effects of Firm-Generated Content in Social Media on Customer Behavior", Journal of Marketing, vol. 80, no. 1, pp. 7-25, 2016. Available: https://doi.org/10.1509/jm.14.0249

[12] F. Wan and F. Ren, "The Effect of Firm Marketing Content on Product Sales: Evidence from a Mobile Social Media Platform." Journal of Electronic Commerce Research, vol. 18, no. 4, pp. 288-302, 2017.

[13] L. De Vries, S. Gensler and P. Leeflang, "Popularity of Brand Posts on Brand Fan Pages: An Investigation of the Effects of Social Media Marketing", Journal of Interactive Marketing, vol. 26, no. 2, pp. 83-91, 2012. Available: https://doi.org/10.1016/j.intmar.2012.01. $\underline{003}$

[14] F. S. Toluna, "Mixing financial, social and fun incentives for social voting." in 18th International World Wide Web conference, Madrid, Spain, 2009.

[15] B. Sellas, "The 5 Cs of Social Media", business2community.com, 2014. [Online], Available on www.business2community.com, [Accessed May 2018].

[16] Y. Zhu and H. Chen, "Social media and human need satisfaction: Implications for social media marketing", Business Horizons, vol. 58, no. 3, pp. 335-345, 2015. Available: https://doi.org/10.1016/j.bushor.2015.01.006

[17] K. Dean, "The 5 Cs of Social Media", www.manobyte.com, 2011. [Online]. Available: https://www.manobyte.com/. [Accessed: 14- May- 2018].

[18] J. Kietzmann, K. Hermkens, I. McCarthy and B. Silvestre, "Social media? Get serious! Understanding the functional building blocks of social media", Business Horizons, vol. 54, no. 3, pp. 241-251, 2011. Available: https://doi.org/10.1016/j.bushor.2011.01.005

[19] A. Kaplan and M. Haenlein, "Users of the world, unite! The challenges and opportunities of Social Media", Business Horizons, vol. 53, no. 1, pp. 59-68, 2010. Available: https:// doi.org/10.1016/j.bushor.2009.09.003 
[20] M. Laroche, M. Habibi, M. Richard and R. Sankaranarayanan, "The effects of social media based brand communities on brand community markers, value creation practices, brand trust and brand loyalty", Computers in Human Behavior, vol. 28, no. 5, pp. 1755-1767, 2012. Available: https://doi.org/10.1016/j.chb.2012.04.016

[21] J. Gallaugher and S. Ransbotham, Gallaugher, J., \& Ransbotham, S. "Social media and customer dialog management at Starbucks", MIS Quarterly Executive, vol. 9, no. 4, pp. 197$211,2010$.

[22] R. Rishika, A. Kumar, R. Janakiraman and R. Bezawada, "The Effect of Customers' Social Media Participation on Customer Visit Frequency and Profitability: An Empirical Investigation", Information Systems Research, vol. 24, no. 1, pp. 108-127, 2013. Available: https://doi.org/10.1287/isre.1120.0460

[23] P. Coelho, P. Correia and I. Medina, "Social Media: A New Way of Public and Political Communication in Digital Media", International Journal of Interactive Mobile Technologies (iJIM), vol. 11, no. 6, pp. 150-157, 2017. Available: https://doi.org/10.3991/ijim.v11 $\underline{\mathrm{i} 6.6876}$

[24] P. Dasgupta, "Economic Progress and the Idea of Social Capital. Social capital: A Multifaceted Perspective.", pp. 325-424, 2000.

[25] S. N. Durlauf, "On the empirics o social capital," The Economic Journal, 112(483), pp. 459479, 2002.

[26] N. B. Ellison, J. Vitak, C. Steinfield, R. Gray and C. Lampe, "Negotiatinfg privacy concerns and social capital needs in a social media environment.", In Privacy Online, pp. 19-32, 2011. https://doi.org/10.1007/978-3-642-21521-6_3

[27] M. Islam, J. Merlo, I. Kawachi, M. Lindström and U. Gerdtham, "Social capital and health: Does egalitarianism matter? A literature review", International Journal for Equity in Health, vol. 5, no. 1, 2006. Available: https://doi.org/10.1186/1475-9276-5-3

[28] Kawachi, B. Kennedy, K. Lochner and D. Prothrow-Stith, "Social capital, income inequality, and mortality.", American Journal of Public Health, vol. 87, no. 9, pp. 1491-1498, 1997. Available: 10.2105/ajph.87.9.1491. https://doi.org/10.2105/ajph.87.9.1491

[29] J. Nahapiet and S. Ghoshal, "Social Capital, Intellectual Capital, and the Organizational Advantage", Academy of Management Review, vol. 23, no. 2, pp. 242-266, 1998. Available: https://doi.org/10.5465/amr.1998.533225

[30] K. Johnston, M. Tanner, N. Lalla and D. Kawalski, "Social capital: the benefit of Facebook 'friends'", Behavior \& Information Technology, vol. 32, no. 1, pp. 24-36, 2013. Available: https://doi.org/10.1080/0144929x.2010.550063

[31] N. Ellison, C. Steinfield and C. Lampe, "The Benefits of Facebook "Friends:" Social Capital and College Students' Use of Online Social Network Sites", Journal of Computer-Mediated Communication, vol. 12, no. 4, pp. 1143-1168, 2007. Available: https://doi.org/10. 1111/j.1083-6101.2007.00367.x

[32] S. Valenzuela, N. Park and K. Kee, "Is there Social Capital in a Social Network Site?: Facebook Use and College Students' Life Satisfaction, Trust, and Participation", Journal of Computer-Mediated Communication, vol. 14, no. 4, pp. 875-901, 2009. Available: https:// doi.org/10.1111/j.1083-6101.2009.01474.x

[33] N. NIE, "Sociability, Interpersonal Relations, and the Internet", American Behavioral Scientist, vol. 45, no. 3, pp. 420-435, 2001. Available: https://doi.org/10.1177/000276401219 $\underline{57277}$

[34] C. Steinfield, N. Ellison and C. Lampe, "Social capital, self-esteem, and use of online social network sites: A longitudinal analysis", Journal of Applied Developmental Psychology, vol. 29, no. 6, pp. 434-445, 2008. Available: https://doi.org/10.1016/j.apdev.2008. $\underline{07.002}$ 
[35] E. Garcia, I. Elbeltagi, K. Dungay and G. Hardaker, "Student use of Facebook for informal learning and peer support", International Journal of Information and Learning Technology, vol. 32, no. 5, pp. 286-299, 2015. Available: https://doi.org/10.1108/ijilt-09-2015-0024

[36] N. Aharony, "What's App: a social capital perspective", Online Information Review, vol. 39, no. 1, pp. 26-42, 2015. Available: https://doi.org/10.1108/oir-08-2014-0177

[37] L. Schiffman, L. Kanuk and J. Wisenblit, Consumer behavior, 11th ed. Upper Saddle River, NJ: Prentice Hall, 2016.

[38] R. Ellington, H. Richard and F. Yammarino, What is culture? Generating and Applying Cultural Knowledge. Edwin Mellen Press., 2010.

[39] F. Furedi, "How the Internet and Social media are changing culture." Aspen Review, Central Europe, vol. 4, pp. 10-13, 2015.

[40] J. Bertot, P. Jaeger and J. Grimes, "Using ICTs to create a culture of transparency: E-government and social media as openness and anti-corruption tools for societies", Government Information Quarterly, vol. 27, no. 3, pp. 264-271, 2010. Available: https://doi.org/10. 1016/i.giq.2010.03.001

[41] J. Van Dijck, The culture of connectivity: A critical history of social media. Oxford University Press, 2013.

[42] E. Giaccardi, Heritage and social media: Understanding heritage in a participatory culture. Routledge. 2012. https://doi.org/10.4324/9780203112984

[43] Steven C. Wheelwright and Kim B. Clark., "Revolutionizing product development: Quantum leaps in speed, efficiency, and quality", New York: The Free Press, 1992.

[44] B. Zirger and M. Maidique, "A Model of New Product Development: An Empirical Test", Management Science, vol. 36, no. 7, pp. 867-883, 1990. Available: https://doi.org/10.1287/ $\underline{\text { mnsc. 36.7.867 }}$

[45] R. Cooper and E. Kleinschmidt, "Benchmarking the Firm's Critical Success Factors in New Product Development", Journal of Product Innovation Management, vol. 12, no. 5, pp. 374391, 1995. Available: https://doi.org/10.1111/1540-5885.1250374

[46] L. Hsieh and S. Chen, "Incorporating voice of the consumer: does it really work?" Industrial Management \& Data Systems, vol. 105, no. 6, pp. 769-785, 2005. Available: https:// doi.org/10.1108/02635570510606996

[47] S. Nambisan, "Designing Virtual Customer Environments for New Product Development: Toward a Theory", Academy of Management Review, vol. 27, no. 3, pp. 392-413, 2002. Available: https://doi.org/10.5465/amr.2002.7389914

[48] M. O'Hern and A. Rindfleisch, "Customer co-creation", Review of Marketing Research, pp. 84-106, 2010. Emerald Group Publishing Limited. https://doi.org/10.4324/9781315088 $\underline{754-4}$

[49] T. Kao, M. Yang, J. Wu and Y. Cheng, "Co-creating value with consumers through social media", Journal of Services Marketing, vol. 30, no. 2, pp. 141-151, 2016. Available: https://doi.org/10.1108/jsm-03-2014-0112

[50] J. Füller, H. Mühlbacher, K. Matzler and G. Jawecki, "Consumer Empowerment Through Internet-Based Co-creation", Journal of Management Information Systems, vol. 26, no. 3, pp. 71-102, 2009. Available: https://doi.org/10.2753/mis0742-1222260303

[51] F. Piller, A. Vossen and C. Ihl, "From Social Media to Social Product Development: The Impact of Social Media on Co-Creation of Innovation", Die Unternehmung, vol. 66, no. 1, pp. 7-27, 2012. Available: https://doi.org/10.5771/0042-059x-2012-1-7

[52] N. Ind and N. Coates, "The meanings of co- creation", European Business Review, vol. 25, no. 1, pp. 86-95, 2013. Available: https://doi.org/10.1108/09555341311287754 
[53] D. Roberts and W. Darler, "Consumer co-creation: an opportunity to humanise the new product development process", International Journal of Market Research, vol. 59, no. 1, p. 13, 2017. Available: https://doi.org/10.2501/ijmr-2017-003

[54] D. Roberts and M. Candi, "Leveraging Social Network Sites in New Product Development: Opportunity or Hype?" Journal of Product Innovation Management, vol. 31, pp. 105-117, 2014. Available: https://doi.org/10.1111/jpim.12195

[55] C. Prahalad and V. Ramaswamy, "Co-creation experiences: The next practice in value creation", Journal of Interactive Marketing, vol. 18, no. 3, pp. 5-14, 2004. Available: https:// doi.org/10.1002/dir.20015

[56] W. Hoyer, R. Chandy, M. Dorotic, M. Krafft and S. Singh, "Consumer Cocreation in New Product Development", Journal of Service Research, vol. 13, no. 3, pp. 283-296, 2010. Available: https://doi.org/10.1177/1094670510375604

[57] C. Fuchs and M. Schreier, "Customer Empowerment in New Product Development*", Journal of Product Innovation Management, vol. 28, no. 1, pp. 17-32, 2010. Available: https://doi.org/10.1111/j.1540-5885.2010.00778.x

[58] K. Chan, C. Yim and S. Lam, "Is Customer Participation in Value Creation a Double-Edged Sword? Evidence from Professional Financial Services across Cultures", Journal of Marketing, vol. 74, no. 3, pp. 48-64, 2010. Available: https://doi.org/10.1509/jmkg.74.3.48

[59] T. Fisher, "ROI in social media: A look at the arguments", Journal of Database Marketing \& Customer Strategy Management, vol. 16, no. 3, pp. 189-195, 2009. Available: https:// doi.org/10.1057/dbm.2009.16

[60] D. Alston, "Social Media ROI—What's the 'Return on Ignoring'?", Marketing Profs, 2009. [Online]. Available: http://www.marketingprofs.com/9/social-media-roi-whats-return-onignoring-alston.asp. [Accessed: 16- Aug- 2018]. https://doi.org/10.1002/9781119199403. $\underline{\mathrm{ch} 13}$

[61] D. Hoffman and M. Fodor, "Hoffman, D. L., \& Fodor, M. (2010). Can you measure the ROI of your social media marketing?", MIT Sloan Management Review, vol. 52, no. 1, p. 41, 2010

[62] Falls, J. (2008). Perhaps social media measurement shouldn't matter. Social Media Explorer. Retrieved from https://socialmediaexplorer.com/social-media-marketing/perhapssocial-media-measurement-shouldnt-matter. https://doi.org/10.1002/9781119370680.fmatter Kumar, V., \& Mirchandani, R. (2012). Increasing the ROI of social media marketing. MIT Sloan Management Review, 54(1), 55.

[64] Y. Choi and A. Thoeni, "Social media: is this the new organizational stepchild? European Business Review, vol. 28, no. 1, pp. 21-38, 2016. Available: https://doi.org/10.1108/ebr-05$\underline{2015-0048}$

[65] K.L. Keller, M. Parameswaran and I. Jacob, Strategic brand management: Building, measuring, and managing brand equity. Pearson Education India. 2013.

[66] E. Relan, "Planning in the era of Algorithms", Brand Equity-Economic Times, p. 2, 2019.

[67] S. Rautela and T. Singhal, "Leveraging Social Media for New Product Development: A Review", Information Technology Journal, vol. 16, no. 3, pp. 91-100, 2017. Available: https://doi.org/10.3923/itj.2017.91.100

[68] T. K. Singhal, "Impact of social media expressions on engagement and trust of customers", Amity Business Review, vol. 17, no. 2, pp. 96-103, 2016.

[69] I. G Medina and P.A.C Pereira, "The importance of Social Media for Commerce. A Case Study in Madeira (Portugal)", International Journal of Interactive Mobile Technologies (iJIM), vol. 6, no.1, pp.37-42, 2012. https://doi.org/10.3991/ijim.v6i1.1825 


\section{$7 \quad$ Authors}

Sonica Rautela is a young professional working as an Assistant Professor at Symbiosis Centre for Management Studies, Pune, India. She is currently pursuing her doctoral degree from Symbiosis International Deemed University Pune, Maharashtra, India. Her interest areas include Social Media, New Product Development, Service Marketing and Brand Management. She has also published research papers in reputed journals. She can be contacted at sonicaonnet@gmail.com

Dr. Tarun Kumar Singhal is associated with Symbiosis Centre for Management Studies, Noida, India as Professor. He is also contributing as Honorary Member at Center of Excellence (CoE) in IT Enabled Services (ITES) Vertical at School of Vocational Education (SVE), Tata Institute of Social Sciences (TISS) Mumbai. He has 25 years of mixed experience in professional/technical education, research and consulting domains. He holds PhD Degree in Business Administration and Masters in Software Systems and Mathematics besides Advanced Diploma in Business Studies and International Certifications from Microsoft (MCSE), Cisco (CCNA) and Brainbench (BCP). He has various credible research publications to his credit. He can be contacted at tksinghal@gmail.com.

Article submitted 2019-03-15. Resubmitted 2019-12-26. Final acceptance 2019-12-30. Final version published as submitted by the authors 